\title{
A REDUÇÃO DE DANOS COMO METODOLOGIA DE PROMOÇÃO DE SAÚDE ÀS PESSOAS EM SITUAÇÃO DE RUA
}

\section{HARM REDUCTION AS A HEALTH PROMOTION METHODOLOGY FOR THE STREET COMMUNITY}

\author{
Luciane Raupp ${ }^{1}$ \\ Daniela Ribeiro Schneider ${ }^{2}$ \\ Gilsenei Tavares Pereira ${ }^{3}$
}

\section{RESUMO}

As transformações epistemológicas na área da saúde resultaram na elaboração de políticas públicas visando a garantia de acesso integral e universal. No Brasil destaca-se a criação do Sistema Único de Saúde - SUS e da Rede de Atenção Psicossocial - RAPS, que possibilita acesso gratuito de saúde à população considerando os determinantes sociais de um país grande em território e desigualdades. Das ações possíveis a partir do SUS e da RAPS está a Redução de Danos, uma estratégia de cuidado que surgiu no país no final dos anos 1980, como resposta à epidemia do HIV/AIDS e, ao longo dos anos, foi ganhando espaço em outros campos de reflexão e intervenção, como a saúde mental e o desenvolvimento social. O presente artigo busca relatar a experiência do processo de adaptação da "Oficina de Redução de Danos" realizada pela equipe de um Centro de Convivência e Cultura durante a Pandemia da COVID-19 e suscitar reflexões sobre os desafios e potencialidades da utilização da Redução de Danos como estratégia de promoção de saúde para pessoas em situação de rua.

Palavras-chaves: Redução de danos; Promoção de saúde; Pessoas em situação de rua; Covid-19.

\begin{abstract}
The epistemological transformations in health care resulted in public policies capable of guaranteeing full and universal access. In Brazil, we highlight the creation of the Sistema Único de Saúde - SUS (Unified Health System) and the Rede de Atenção Psicossocial - RAPS (Psychosocial Care Network). These provide free access to health care for the population considering the social determinants of a large country in terms of territory and inequalities. Among the actions by the SUS and RAPS is Harm Reduction. This care strategy emerged in the country in the late 1980s as a response to the HIV/AIDS epidemic and, over the years, has been gaining ground in other fields, such as mental health and social development. This article reports the "Harm Reduction Workshop" experience
\end{abstract}

\footnotetext{
${ }^{1}$ Doutora em Saúde Pública pela Universidade de São Paulo (USP). Mestra em Psicologia Social e Institucional pela Universidade Federal do Rio Grande do Sul (UFRGS). e-mail: lucianemraupp@gmail.com

2 Atualmente é Professora Titular do Departamento de Psicologia da Universidade Federal de Santa Catarina (UFSC). Pós-Doutora em Ciência da Prevenção (Universidad de Valencia - España, 2012 e University of Miami USA, 2019). Doutora em Psicologia pela Pontifícia Universidade Católica de São Paulo (PUC- SP). Mestra em Educação pela Universidade Federal de Santa Catarina, UFSC. e-mail: danischneiderpsi@gmail.com

${ }^{3}$ Atualmente faz parte do quadro de profissionais da Psicologia no Projeto Resgate Social, vinculado à Secretaria de Assistência Social de Florianópolis - SC. Graduado em Psicologia pela Universidade Federal de Santa Catarina - UFSC. e-mail: gilseneit@gmail.com
} 
implemented by the Centro de Convivência e Cultura (Center of Culture and Coexistence) during the COVID-19 Pandemic, a group activity with people who use drugs in a vulnerable context. It also seeks to spark reflections on the challenges and potential of using Harm Reduction as a health promotion strategy for the street community.

Keywords: Harm reduction; Health promotion; Street community; Covid-19.

\section{INTRODUÇÃO}

A atenção à população em situação de rua no Brasil é um grande desafio, na medida em que vem marcada pelo embate entre políticas de caráter higienista-assistencialista e a de lutas por direitos sociais. Estas pessoas são tratadas socialmente como 'descartáveis urbanos', cujos direitos básicos de cidadania são negados, por serem pessoas cujas trajetórias existenciais são permeadas pelo estigma e pela discriminação (VARANDA; ADORNO, 2004).

A pandemia do Sars-Cov-2, vírus causador da Covid-19, agravou a situação já insustentável de um país onde as desigualdades sociais são estruturais e atingem proporções abissais. Trouxe agravos à saúde relacionados não só à doença em si, mas às suas consequências sociais, como menor crescimento econômico, aumento dos níveis de pobreza, do desemprego, do déficit habitacional e um aumento vertiginoso da fome e da insegurança alimentar. Autores como Santos e Cols (2020) produziram dados que advertem que, em tempos de pandemia, as desigualdades sociais produzem impactos diversos, segundo o lugar social ocupado pelos grupos. Nesse sentido, as assimetrias que a emergência sanitária global reflete e produz deixam segmentos específicos da população mais vulneráveis ao adoecimento e morte, especialmente a população negra.

Uma das consequências desse processo é que desde meados de 2020 se faz visível nas ruas das médias e grandes cidades do país o aumento da população em situação de rua, inclusive com a presença significativa de pessoas adentrando pela primeira vez nessa condição (Natalino, 2020). Isto num contexto que exige medidas de isolamento social, coloca em destaque as dificuldades de lidar com essa crise sanitária por parte dos indivíduos mais vulneráveis. Nessa direção, nota-se que a referida situação leva à seguinte reflexão

A necessidade de isolamento social e higiene para quem não tem sequer moradia (ou dispõe de residências provisórias coletivas) e a limitação repentina e severa dos já precários meios de sobrevivência (doações e pequenos serviços), aprofundam o abismo social que esse grupo vivencia" (NATALINO, 2020, p. 8). 
Assim, tem-se como foco deste artigo a problematização dos meios possíveis para lidar com a crise representada pela pandemia no tocante às pessoas em situação de rua (BRASIL, 2009). Para tanto, busca-se apresentar, no formato de relato de experiência, o processo de adaptação da "Oficina de Redução de Danos", desenvolvida por uma organização nãogovernamental (ONG) na cidade de Florianópolis/SC como uma oficina do Centro de Convivência e Cultura (CECO), dispositivo da Rede de Atenção Psicossocial desta cidade em parceria com a Rede Municipal de Saúde. Vale ressaltar, que diante da situação de emergência sanitária a ONG foi fechada para o público externo e passou a desenvolver suas atividades de convivência junto a um projeto denominado "Passarela da Cidadania", projeto em parceria entre a Prefeitura Municipal de Florianópolis e uma outra organização da sociedade civil que gerencia este espaço.

Com base no foco citado pretende-se aqui problematizar a Oficina de Redução de Danos como metodologia de promoção de saúde às pessoas em situação de rua no contexto da pandemia, por meio do arcabouço conceitual do campo da Saúde Coletiva, e em especial, da discussão sobre Promoção de Saúde e Redução de Danos.

\section{SAÚde NO BRASIL: A CONSTRUÇÃo PAUlatina de POLíticas DE PROMOÇÃO À SAÚDE}

O processo de ampliação do conceito de saúde precedido pela $8^{\text {a }}$ Conferência Nacional de Saúde (BRASIL, 1986), sob influência da Conferência Internacional sobre Promoção da Saúde (WHO, 1986), impulsionou grandes mudanças na área da Saúde Coletiva. No Brasil, dois anos após a conferência, a Constituição Cidadã (1988) inovou com artigos que garantiam o direito à saúde nos moldes do conceito ampliado como direito de todos e dever do Estado, prescrevendo assim, uma política nacional para a área que viria a se estabelecer como Sistema Único de Saúde (SUS), em 1990 (BRASIL, 1990).

A partir dos direitos sociais adquiridos notadamente dentro dessa área, os quais significaram a consagração das reivindicações do povo brasileiro, nota-se que a construção do 


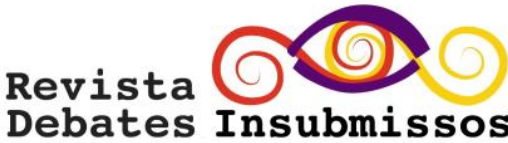

sistema de saúde brasileiro não se deu de maneira orgânica e estável politicamente, sendo que ainda hoje encontram-se no campo político e epistemológico forças divergentes, que buscam interferir nos rumos da política de saúde. Tornar-se-ia evidente, ao observar a história da saúde pública no Brasil, a importância da existência de um sistema de saúde público que garante o acesso a serviços de promoção e prevenção de forma integral e gratuita a toda população. A despeito de o sistema de saúde brasileiro enfrentar resistências desde sua implantação e sofrer de um crônico subfinanciamento (FUNCIA, 2019), destacou-se globalmente pelo avanço que representou em termos de política pública.

O referido avanço em muito se deve aos seus princípios organizativos, a saber: a) os que visam garantir acesso universal aos serviços de saúde, em todos os níveis de assistência; b) a integralidade, que garante assistência integral combinando ações e serviços de promoção, prevenção, atenção e curativa em saúde de forma individual e coletiva em todos os níveis de complexidade; c) a participação popular, a qual garante à população o controle e avaliação dos serviços e políticas públicas de saúde através de sua participação nos Conselhos e Conferências de Saúde. Cabe destacar que no contexto atual de pandemia, a existência do SUS salvou vidas, demonstrando que a contrarreforma em curso há alguns anos na área das políticas de saúde, saúde mental e atenção às pessoas que usam drogas compromete os avanços alcançados na área desde os anos 1980, na esteira das reformas sanitária e psiquiátrica brasileiras (FUNCIA, 2019).

Para Campos (2009), a ampliação do conceito de saúde exige a articulação interdisciplinar entre áreas de saber técnico, científico e popular e a integração de outros olhares e modelos de cuidado para além do biomédico. Torna-se necessário estabelecer articulações intersetoriais e estratégias de cuidado capazes de dar conta das múltiplas demandas oriundas das determinações sociais à saúde, em um país onde coexistem muitos problemas sociais, principalmente ligados ao colonialismo e racismo que determinam os lugares e a esfera de possíveis da população. Ainda segundo este autor, para dar conta desses desafios, a área da saúde tornou-se mais complexa e rica ao se aproximar do campo das Ciências Humanas e Sociais, recebendo importantes contribuições de áreas como Antropologia, Ciências Sociais, Educação, Artes, entre outras. 


\section{Revista \\ Debates Insubmissos}

Para uma compreensão da importância da influência da esfera social sobre a determinação dos processos de saúde-doença das populações, a noção de Determinantes Sociais e de Saúde (DSS) passou a adquirir relevância na definição de políticas de saúde, atentando para o papel das iniquidades nas condições de saúde e no acesso aos serviços públicos em geral, com destaque ao papel das condições de vida (XIMENES et al., 2016), sendo considerada base para a formulação da Política Nacional de Promoção da Saúde (BRASIL, 2002). Segundo a Organização Mundial da Saúde (OMS), os determinantes sociais em saúde são "as condições em que as pessoas nascem, crescem, vivem, trabalham e envelhecem" (WHO, 2011, p. 44), os quais acabam por determinar as condições de vida e de saúde. Exemplificando, as privações de renda ao se articularem a outras carências e vulnerabilidades, impactam as condições de existência sobre o adoecer, portanto, os efeitos macroestruturais de uma sociedade, como a economia, cultura, história e sociodinâmica afetam as condições específicas de cada território e dos grupos sociais. Assim, ao planejar ações no âmbito da promoção de saúde deve-se considerar o papel das interseccionalidades, como as de raça, etnia, gênero, idade, classe social, entre outras, e seus impactos nas trajetórias e experiências individuais (XIMENES et al, 2016). Nota-se então, que para compreender os DSS são considerados os múltiplos aspectos da vida que vão desde as organizações coletivas aos modos de vida individuais (BARATA, 2009; SCHNEIDER et al., 2019).

O campo da promoção de saúde visa incidir sobre as condições de vida da população e propõe um novo paradigma que integra conceitos e ideias advindos de diferentes disciplinas, tais como a educação, a saúde, o território, o trabalho, a alimentação, o meio ambiente, o acesso a serviços essenciais e ao lazer (SÍCOLI; NASCIMENTO, 2003). Esta perspectiva visa à autonomia dos sujeitos e coletividades e, assim, reflete e inspira mudanças significativas nas formas de atuar em saúde. Nesse sentido, busca empoderar os sujeitos e fortalecer recursos individuais e coletivos, para que se possa lidar com a multiplicidade dos DSS (CZERESNIA, 2003), almejando fortalecer a saúde através da construção da capacidade de escolha via ampliação do conhecimento e da percepção das diferenças e das singularidades dos fatos. 
A partir deste campo, dentre as novas ações e práticas em saúde mental que então surgem, destaca-se a Redução de Danos (RD), compreendida como um paradigma inovador, assumido pelo SUS e pelas políticas de saúde mental como orientação ético-política e metodológica de ações na área de álcool e outras drogas (BRASIL, 1990; 2003). Tal como a Promoção de Saúde, essa perspectiva também enfatiza a autonomia das pessoas que usam drogas, porém, de forma diferente dos tratamentos "tradicionais", calcados no modelo biomédico. Neste, os problemas relativos ao uso de álcool e outras drogas são concebidos como uma doença cerebral e crônica, com ênfase nas determinantes neuroquímicas, colocando a dependência como incurável e dando ênfase em tratamento medicamentoso ou de cunho moral, de modo a limitar os sujeitos em seus horizontes de possibilidades (SCHNEIDER, 2010).

Em suma, a Redução de Danos ou RD, enquanto conjunto de estratégias de cuidado ou um novo paradigma, se aproxima dos princípios da Promoção de Saúde ao considerar os DSS; preconizar intervenções participativas; propor ações que tem como foco a saúde da população em geral, no seu ambiente, em detrimento da doença em um grupo de risco; estabelecer abordagens focadas na facilitação e na capacitação dos sujeitos considerando-os autores do próprio processo e, enfim, ao transferir o foco das ações do problema/doença para as potências de cada um ou de seus grupos e para a promoção da qualidade de vida (MOREIRA, 2006).

\section{REDUÇÃo DE DANOS COMO ESTRATÉGIA DE PROMOÇÃo DE SAÚdE ENTRE A POPULAÇÃO EM SITUAÇÃO DE RUA E USUÁRIOS DE DROGAS}

A RD surge no Brasil como uma alternativa para abordar a temática do uso de drogas, modificando o olhar moralista e patológico do usuário como um doente, criminoso ou pecador. Ao ter como foco o acolhimento à diversidade das situações humanas, colocando o sujeito e suas diversas relações materiais e sociais como centro de sua compreensão e intervenção, a Redução de Danos ampliou as ações de saúde para além da relação do usuário com a droga, passando a estabelecer uma abordagem que considera o bem-estar integral do sujeito, fugindo da rigidez da visão da adição como uma doença crônica, como mencionado anteriormente. Nesse sentido, as ações da RD buscam promover saúde dando luz a outras relações possíveis 


\section{Revista \\ Debates Insubmissos}

da pessoa com o seu mundo, sem negar ou impedir as relações significativas para o sujeito, inclusive com a droga, ou sem reforçar estigmas.

De acordo com Mesquita (2020), entre as ações pioneiras de RD no Brasil destaca-se a proposta de trocas de seringas para pessoas que faziam uso de drogas injetáveis no município de Santos - SP, em 1989. A ação se deu a partir do I Seminário Santista sobre Aids, no mesmo ano, visando reduzir o contágio de HIV/Aids entre os usuários de cocaína injetável. À época, o grupo representava 50\% dos casos de Aids no município o que demandou como medidas do programa a distribuição de preservativos em toda rede municipal, a compra de medicamentos antirretrovirais e a oferta de seringas a usuários de drogas injetáveis para evitar o compartilhamento de utensílios para o uso. Assim, apesar da RD ter surgido associada à diminuição do contágio de doenças sexualmente transmissíveis (DSTs), foi possível ampliar a aplicação de seus princípios e metodologias participativas, como uma estratégia de promoção de saúde, para além das infecções sexualmente transmissíveis (IST-s).

Um importante autor que se debruça sobre a história das políticas de drogas em geral, e da RD em particular, é Denis Petuco. No artigo "As três ondas da Redução de Danos no Brasil" (PETUCO, 2020), ele apresenta o nascimento da Redução de Danos em Santos-SP como o surgimento da primeira onda, evidenciando os processos que levaram as autoridades de saúde a conceber a AIDS não apenas como doença relacionada apenas a um vírus, mas como fenômeno social que coloca em evidência a necessidade de considerar o debate sobre temastabu, como a sexualidade e o uso de drogas, para lidar de forma efetiva com a epidemia do HIV/Aids.

Um dos aspectos históricos que levou à segunda onda da RD no Brasil foi o aumento do consumo de crack em todo país. Esse processo fez com que o uso de drogas injetáveis reduzisse ao ponto de se tornar epidemiologicamente irrelevante, com isso os recursos do Departamento de IST, HIV/Aids e Hepatites Virais do Ministério da Saúde reduziram impossibilitando as ações que vinham sendo executadas. A responsabilidade sobre as políticas de uso de álcool e outras drogas passaram a ser da Coordenação Nacional de Saúde Mental, Álcool e Outras Drogas (a partir de 2002) e, por conta disso, diversas organizações de Redução de Danos 
diminuíram ou encerraram suas atividades e os Programas de Redução de Danos (PRD) passaram a ser subordinados à saúde mental. Apesar dos processos históricos apontarem para a transformação das experiências com RD como respostas à epidemia do HIV/Aids, ela não se tornou uma estratégia ineficaz, uma vez que a prevalência do HIV/Aids entre os brasileiros que fazem uso do crack é oito vezes maior que na população em geral (BERTONI; BASTOS, 2014).

Como já dito, o aumento do uso de crack no país foi uma das causas precursoras da segunda onda da Redução de Danos no Brasil. Esse acontecimento gerou um campo de conflito entre entidades contrárias à Reforma Psiquiátrica Brasileira (Associação Brasileira de Psiquiatria e alguns sindicatos médicos) e aquelas defensoras da Reforma. Na ocasião (meados de 2000), as entidades contrárias denunciavam nas mídias a dispersão do uso de crack pelo país como consequência do fechamento de hospitais psiquiátricos. $\mathrm{O}$ ataque teve como consequência a efetiva articulação entre os movimentos de Saúde Mental e de HIV/Aids, que já vinha sendo ensaiado desde o final da década de 1990. Como um dos marcos desse encontro e da segunda onda da RD no Brasil foi lançada a Política de Atenção Integral para Pessoas que usam Álcool e Outras Drogas (BRASIL, 2003), documento que apresentava pela primeira vez a RD como diretriz de cuidado no Sistema Único de Saúde. Mesmo assim, ao contrário do que aconteceu na primeira onda, a política não oferecia respostas concretas para a prática de RD no campo da saúde mental, mas induzia a elaborações criativas a partir de imperativos éticos e diretrizes políticas para o campo.

Além da Política de Atenção Integral para Pessoas que usam Álcool e Outras Drogas, outros marcos importantes da segunda onda foram o "Projeto Caminhos do Cuidado", a transformação do Consultório de Rua em Consultório na Rua, a inclusão de redutores e redutoras de danos em equipes de CAPSad em algumas cidades brasileiras e a transformação de algumas organizações não governamentais (ONGs) de Redução de Danos na direção ao campo da saúde mental.

A terceira onda, por sua vez, surge como um acúmulo dessas experiências. O movimento da RD é levado a perceber que para promover saúde é preciso reduzir o dano da desigualdade social, da violência, do racismo institucional e estrutural e do encarceramento 
gerado pelas dinâmicas dos mercados de drogas. Assim, constitui-se uma ampla articulação intersetorial que visa concretizar o cuidado integral como a proteção à vida, acesso à educação, cultura, direitos humanos e assistência social, renda, trabalho e moradia, além dos cuidados em saúde. Na terceira onda, a redução de danos é cobrada a reconhecer as interseccionalidades dos problemas relacionados ao uso de drogas como as questões de raça, gênero, classe e orientação social. Destacam-se, a partir daí, os Projetos Terapêuticos Singulares (PTS) construídos nos CAPS, o "Programa Atitude" em Pernambuco (2011), Programa "Corra Pro Abraço" na Bahia (2013), Programa “De Braços Abertos” em São Paulo (2014) e, à nível nacional, o "Projeto Redes" (2014) criado pela Secretaria Nacional de Políticas sobre Drogas (SENAD).

Nessa direção, o esforço de Petuco (2020) em apresentar a história da Redução de Danos no Brasil como ondas nos convida a olhar para os processos não como uma ruptura, mas como um acúmulo crítico dessas experiências que se deram em tentativas de estabelecer bons encontros.

É importante ressaltar que o estabelecimento da RD como princípio organizativo das políticas públicas de álcool e outras drogas se contrapõe à proposta hegemônica da política proibicionista que propõe "guerra às drogas" e produz consequências devastadoras às pessoas que fazem uso de drogas ilícitas. Os impactos do proibicionismo e da "guerra às drogas" se materializam na estigmatização das pessoas que fazem uso de drogas e, consequentemente, produz um processo de marginalização dos usuários, obrigando-os a fazer o uso de forma isolada e de substâncias de má qualidade que são produzidas através do mercado ilegal de drogas, além de dificultar o acesso aos serviços de saúde, quando necessário. (RIBEIRO; BELLINI JR, 2020).

Com relação a existência do comércio ilegal de drogas, ela é também uma das responsáveis pelo processo de seletividade penal, visto que cerca de $20 \%$ das incidências penais estão relacionadas a delitos de drogas (BRASIL, 2020a), sendo uma situação atravessada pelas interseccionalidades raciais (maioria negros), de gênero (maioria homens), de idade (maioria jovens), de classe social (maioria de classe baixa). A violência gerada pelas intervenções policiais nas favelas tem trazido como consequência drástica o aumento significativo do 
genocídio de jovens negros, o que afeta diretamente o processo de saúde pública, não só das pessoas que fazem uso de drogas ilícitas, mas de comunidades que se encontram em situação de vulnerabilidade social (MINAYO, 2006; BUENO, 2019).

Fruto direto das desigualdades sociais e iniquidades em termos de políticas públicas encontra-se a população em situação de rua. Uma revisão integrativa descreve as razões que levam pessoas a viverem nas ruas, seja de forma passageira ou mais definitiva, sendo que:

[...] a precarização das condições de vida é uma delas, porém reduzir a compreensão do fenômeno a questões econômicas limita sua compreensão e reduz a complexidade que o conota. (...) Os principais motivos relatados que levaram as pessoas a viver nas ruas é o uso abusivo de álcool e outras drogas $(35,5 \%)$, o desemprego $(29,8 \%)$ e conflitos familiares (29,1\%)" (SICARI; ZANELLA, 2018, p. 664).

A discussão do tema prossegue para a inclusão da escolha pessoal como uma destas razões, na medida em que muitas pessoas em situação de rua justificam a busca pela sensação de liberdade como a principal motivação (SICARI; ZANELLA, 2018). Tais razões nos remetem à reflexão da importância do emprego dos princípios e metodologia da Redução de Danos junto à essa população, por justamente ser uma perspectiva que parte da acepção da condição de liberdade do sujeito, aberta à diversidade de modos de vida e experiências existenciais, que se coloca como uma abordagem nas questões ligadas ao Álcool e outras Drogas com foco na inclusão social, corresponsabilização, e minimização de danos como forma de valorizar a vida, garantir direitos e promover saúde.

\section{METODOLOGIA}

Esse trabalho é fruto de reflexões geradas num contexto de práticas psicossociais e culturais realizadas num Centro de Convivência e Cultura (CECO) - parte da RAPS do município de Florianópolis/SC, no espaço da Oficina de Redução de Danos. Configura-se como um relato de experiência. Um relato é uma narração detalhada de experiências vividas, onde o assunto é abordado sob o ponto de vista de quem o relata. Sobre a perspectiva metodológica é uma forma de narrativa que busca representar acontecimentos vividos, experiências 
profissionais, entre outras, de modo que o que é narrado são acontecimentos vividos, de forma detalhada (GROLLMUS; TARRÉS, 2015).

O relato abrange o período entre os meses de janeiro de 2020 à março de 2021, período de pandemia de COVID-19, quando o projeto passou a ocorrer no sambódromo municipal Passarela da Cidadania, localizado na região central da cidade. Os acontecimentos narrados e as técnicas utilizadas foram registrados nos relatórios de gestão da entidade, fonte da qual foram retirados os registros para a descrição dos encontros.

\section{DESCRIÇÃO E DISCUSSÃO}

A experiência relatada neste artigo ocorreu durante o ano de 2020, quando os serviços de saúde e assistência social tiveram que se reorganizar no município de Florianópolis/SC, para dar conta da demanda causada pela pandemia. Tem por foco o trabalho desenvolvido pelo Centro de Convivência e Cultura (CECO), projeto ligado à Secretaria Municipal de Saúde de Florianópolis, executado pelo Instituto Arco-íris de Direito Humanos que oferece atendimento psicológico e oficinas terapêuticas à comunidade da região.

O Instituto Arco-íris é uma Organização da Sociedade Civil de Interesse Público (OSCIP) que trabalha com populações em situação vulnerável (NÓR; CAVANUS; ARAUJO DE SOUZA, 2018). Iniciou suas atividades em 1997 trabalhando com promoção de saúde para profissionais do sexo na perspectiva da Redução de Danos e dos Direitos Humanos (INSTITUTO ARCO-ÍRIS, 1997). Com o passar do tempo, ampliou suas atividades se tornando um espaço de referência em cultura, promoção de saúde e cidadania. Um espaço que funciona de portas abertas e proporciona o convívio diário entre pessoas de diferentes condições e experiências de vida.

Por ser um Centro de Convivência, o Instituto Arco-íris é reconhecido como um local acolhedor, localizado no centro da cidade, que trabalha na perspectiva da Redução de Danos e disponibiliza acesso a direitos básicos como internet, leitura, higiene, água, lazer, descanso, cultura a usuários da RAPS do município e pessoas em situação de rua ou de vulnerabilidade 


\section{Revista \\ Debates Insubmissos}

psicossocial. Segundo Rigoni, Breeksema e Woods (2019) os centros de convivência são uma estratégia de RD de baixa exigência, com evidências estabelecidas cientificamente, presentes em vários países. Estes equipamentos promovem saúde por fornecerem apoio social na comunidade, particularmente para os grupos marginalizados como trabalhadoras/es sexuais, pessoas em situação de rua e pessoas que usam drogas (RIGONI; BREEKSEMA; WOODS, 2019).

A convivência entre estudantes, público LGBTQIA $+{ }^{4}$, trabalhadores, pessoas em situação de rua, usuários da RAPS, artistas e outros grupos, era constante no espaço original do projeto (FERREIRA, 2012), antes de a situação de emergência sanitária trazer a necessidade de mudança de local de atuação. Uma das atividades que ocorriam periodicamente nesse espaço era a Oficina de Redução de Danos (RD) - foco desse relato -, atividade pensada para propor uma relação de escuta acolhedora entre as diversas experiências de vida dos que buscavam esse espaço de interação e cuidado. Os encontros da Oficina de Redução de Danos aconteciam semanalmente, durante duas horas. Por meio da aplicação de dinâmicas grupais, rodas de conversas, músicas, projeção de vídeos, participação de convidados e realização de saraus culturais, eram apresentadas e trabalhadas noções de RD, elencadas de acordo com as demandas e experiências do grupo. O trabalho tinha por base a mediação entre pares, baseada na contratação de pessoas que são ou já foram usuários/as de drogas ou estiveram em situação de rua como membros da equipe. A abordagem social promovida por pares é amplamente aceita pois efetivamente facilita o acesso e o desenvolvimento de ações para engajar os usuários de drogas e outras populações marginalizadas e difíceis de alcançar (RIGONI; BREEKSEMA; WOODS, 2019).

Dessa forma seguiam as atividades do local até o mês de março de 2020 quando o local foi fechado ao público externo devido aos decretos municipais que reduziam o funcionamento das instituições abertas ao público, devido à pandemia da Covid-19. Como resposta a essa inevitabilidade, o instituto uniu-se a outras 19 instituições e coletivos da cidade, formando a

\footnotetext{
${ }^{4}$ Sigla do movimento político e social que luta e defende os direitos pela diversidade de gênero e sexualidades. Significa: Lésbicas, Gays, Bissexuais, Transgêneros, Transsexuais e Travestis, Queer, Intersexuais, Assexuais e outros grupos e variações de sexualidades e gênero, como por exemplo a pansexualidade.
} 


\section{Revista \\ Debates Insubmissos}

associação "Rede com a Rua" que "tem por objetivo disponibilizar à população em situação de rua apoio às suas necessidades, garantindo a sua dignidade e fruição de direitos, de forma continuada e programada, em processo de aproximação, escuta qualificada, e a gradativa construção de vínculos de confiança" (REDE COM A RUA, 2020). Tensionado pela Rede Com a Rua, o poder público municipal ampliou as vagas de acolhimento às pessoas em situação de rua de forma emergencial durante a pandemia e passou a oferecer mais vagas de abrigo e alimentação no complexo da passarela de samba da cidade, denominada "Nego Quirido", a partir do projeto denominado de "Passarela da Cidadania".

Essa ação se deu consoante com as orientações disponibilizadas em nota técnica do governo federal que recomenda ações específicas para a população em situação de rua durante a pandemia. Estas preveem, por exemplo, medidas de acolhimento regular e provisório; mobilização das entidades da sociedade; atenção a situações específicas, como uso abusivo de álcool e outras drogas, migrantes, crianças e adolescentes, e segmento LGBTQIA+, todos em situação de rua (BRASIL, 2020b).

A Passarela da Cidadania é um projeto voltado à jovens, adultos e idosos em situação de rua da Secretaria Municipal de Assistência Social de Florianópolis-SC, executado por Organizações Não Governamentais (ONGs) que concorrem anualmente a editais específicos para a realização do projeto no complexo da passarela Nego Quirido. Antes da pandemia, e de acordo com o Termo de Colaboração n 061/PMF/SEMAS/2019, o projeto previa oferecer prestação de serviços a até 150 pessoas em situação de rua através da disponibilização de alimentação (café da manhã, almoço e janta), serviços de higiene pessoal (banho, higiene bucal, corte de barba e cabelo), acesso à espaços de guarda de pertences, higienização de roupas, acesso a atividades complementares, além de equipes de sensibilização para atuar junto às pessoas em situação de rua na região central do município. Conta também com atendimento técnico executado por assistente social e psicólogo(a).

A demanda se tornou maior com a pandemia e o espaço chegou a ter aproximadamente 300 pessoas acolhidas de forma emergencial. Com a situação, a Rede com a Rua ocupou o local, visando colaborar com o acolhimento emergencial por meio da distribuição de refeições, 
doações de roupas e calçados, atendimento jurídico, oferta de oficinas terapêuticas, cuidados aos animais das pessoas acolhidas no espaço, acompanhamento psicossocial, auxílio na organização pessoal e domiciliar, na segurança alimentar e nutricional e na geração de renda para pessoas que estavam em processo de transição da rua para casa (ASSOCIAÇÃO BENEFICENTE REDE COM A RUA, 2020). O surgimento de ações semelhantes oriundas da sociedade civil organizada foi reportado em diversas cidades durante a pandemia, nas quais ações emergenciais comunitárias auxiliaram no atendimento das necessidades básicas, como redução da insegurança alimentar e melhora nas condições de moradia (SANTOS et al., 2020).

Nessa situação, a Oficinas de Redução de Danos, que até então, eram oferecidas na sede do instituto Arco-íris, com toda estrutura e suporte necessários, passaram a ser realizadas improvisadamente na Passarela da Cidadania. Este fator modificou a dinâmica de realização dessas oficinas, reduzindo o número de participantes assíduos e evidenciando a necessidade de sua adaptação às novas condições sociais. Dada às condições precárias de vida da população em situação de rua, não havia possibilidade de planejar ações de forma remota, sendo que as oficinas continuaram a serem oferecidas de modo presencial, buscando, dentro do possível, manter as regras sanitárias para evitar o contágio do coronavírus, desafio que passaremos a descrever abaixo.

Frente a tal cenário, foi proposta a utilização dos encontros da Oficina de Redução de Danos como dispositivo para debater a situação da pandemia e os cuidados necessários nesse contexto. Assim, as primeiras oficinas de RD na Passarela abordaram, através de rodas de conversas e projeção de materiais audiovisuais, informações sobre a doença, sobre as regras impostas pelas gestões municipais, estaduais e federais e os cuidados de prevenção à transmissão do vírus.

No entanto, logo se evidenciou que a metodologia utilizada não era adequada devido à dinâmica que então se colocava no local, pois, enquanto a Oficina de RD trabalhava medidas de distanciamento social e prevenção de transmissão de COVID, a situação complexa da Passarela da Cidadania ia na contramão do trabalho executado, promovendo aglomerações, com pessoas sem usar máscaras, ou sem usá-las adequadamente, e ausência de distribuição de 


\section{Revista \\ Debates Insubmissos}

equipamentos de proteção individual (EPIs). Os oficineiros e participantes externos participavam das oficinas portando EPIs, com máscaras e luvas, com intuito de reforçar a necessidade de sua utilização, entretanto, percebeu-se que a falta de oferta destes materiais para os acolhidos evidenciava a desigualdade social e, ainda, prejudicava o vínculo.

Frente a este desafio, foi necessário transformar o discurso em ação para efetivamente promover saúde e, passou-se então a buscar articulação com outros setores da sociedade para promover atividades de produção e doação de EPIs, como máscaras e produtos de higiene, a fim de suprir essa necessidade.

Além dos EPIs, outro desafio para a adaptação da Oficina de Redução de Danos na Passarela da Cidadania era a necessidade de afastamento social em um local onde havia inicialmente apenas barracas e colchões amontoados em grandes alas coletivas, evidenciando que o afastamento social não era uma possibilidade real devido às condições físicas do local. Essa realidade, no contexto da Oficina de Redução de Danos trouxe a dificuldade adicional de manter o formato de roda de conversa que a mesma possuía para facilitar a interação. Nesse contexto, a única estratégia possível para garantir o afastamento era lembrar constantemente aos participantes da necessidade de ficarem fisicamente afastados. Tal ação se demonstrava paradoxal, uma vez que bastava olhar a condição local para perceber que não havia a estrutura necessária para garantir segurança.

Com o tempo, percebemos que para garantir minimamente o afastamento durante a oficina precisávamos agir não apenas na conscientização dos participantes, mas na reivindicação de um espaço cultural com estrutura que garantisse as condições de afastamento. Mais tarde, a oficina passou a ser realizada num canto da passarela com disponibilização de $\mathrm{TV}$, microfones, mesas e cadeiras que facilitaram um pouco mais o afastamento social dos participantes. Ainda não era o ideal, mas produziu maior privacidade para a ação e permitiu que a mesma fosse executada em espaço aberto.

A necessidade de adaptação não foi exclusiva à oficina de Redução de Danos, pois todos os serviços de saúde e socioassistencial precisaram se adaptar às novas exigências. Apesar disso, a oficina de RD possibilitou um espaço livre para receber informações sobre saúde e 
refletir sobre os impactos da pandemia, bem como sobre as necessidades de adaptação e as estratégias possíveis para a realização da promoção de saúde e prevenção às doenças, de acordo com as condições locais.

Em 2020 aconteceram diversos encontros da Oficina de Redução de Danos, entretanto, eles não eram realizados conforme planejado, devido a episódios de conflito no local, por exemplo. Nesses momentos, esta oficina foi precursora de espaços organizativos dos acolhidos na Passarela da Cidadania realizando assembleias para refazer acordos de convivência e propiciar espaços de voz aos usuários para com a direção e técnicos locais - embora estes nem sempre fossem posteriormente acolhidos pela direção.

Assim, os primeiros meses foram marcados por encontros que enfatizavam a necessidade de prevenção por parte de todos contra a transmissão da Covid-19, propiciando reflexões sobre as condições arquitetônicas da Passarela, levando em conta as dinâmicas e necessidades das pessoas. Somente após atribuir ao discurso a prática da prevenção de doenças no contexto de vulnerabilidade social é que foi possível retomar para o processo de promoção de saúde como planejado inicialmente.

Um dos fatores que levou à possibilidade de realizar ações de promoção de saúde na Passarela da Cidadania foi o aumento do uso de substâncias psicoativas no local. O tema passou a ser demandado pelos próprios participantes da oficina, como forma de lidar com a situação, dado o risco que trazia para gerar violência e acabar por permitir a entrada da polícia no espaço. Essas diretrizes, que guiaram a construção do trabalho na Oficina de $\mathrm{RD}$, foram condizentes com o papel que deve ser desempenhado por um centro de convivência, segundo Rigoni, Breeksema e Woods (2019, p. 43)

O apoio à autorregulação e às estratégias dos usuários para obter ou manter controle sobre seu uso de drogas se articula com uma abordagem de redução de danos que visa regular o uso de drogas e empoderar os usuários (FDTI, 2014). Também se articula com uma abordagem bottom up (de baixo para cima) de redução de danos, que enfatiza a capacidade do usuário de controlar seu uso e reduzir seus riscos.

A partir dos encontros, foi possível perceber que um dos motivos que levava ao uso abusivo de substâncias psicoativas no espaço era o ócio, uma vez que haviam poucas atividades. A partir disso, a Oficina de RD em articulação com outros setores da sociedade, como a Rede 
com a Rua, o Movimento de População de Rua e com os próprios acolhidos iniciou estratégias de promoção de saúde através da construção de uma biblioteca no local (chamado de "Gelateca" por ter sido construída no interior de um eletrodoméstico); a aquisição de jogos para construção de um espaço de lazer; de um tapete de dança para realização de uma oficina de hip hop, facilitada pelos próprios acolhidos no espaço; realização de cine debates com pessoas convidadas; ações de cortes de cabelos; oferecimento de momentos de livre expressão cultural e artísticas, por meio da realização de saraus mensais com a dinâmica de microfone aberto. Também foram improvisadas exposições e expressões de pinturas, escritas, leituras e músicas, parcerias com projetos de fotografia onde os participantes tinham acesso a máquinas fotográficas para fotografar sua rotina ou serem fotografados e rodas de conversas sobre violência, sexualidades, gênero, raça, uso de substâncias lícitas e ilícitas, significados da Passarela da Cidadania, experiências da rua, entre outros.

Sendo assim, a experiência com a Oficina de RD não foi executada de maneira isolada. A articulação com as equipes de Consultórios na Rua, com serviços socioassistenciais do município, com outros projetos do próprio Instituto Arco-íris e com organizações da sociedade civil foram constantes e necessárias, indicando que para prevenir o aumento de casos de Covid19 entre uma população que vive às margens do acesso aos direitos básicos, há a exigência de uma ação articulada que considere múltiplos condicionantes sociais. Destacaram-se nesse processo a necessidade de trabalhar com temáticas que abordassem como as dinâmicas sociais existentes entre os grupos em situação de rua, os efeitos das violências de gênero, classe e raça e suas intersecções e influências nos padrões desadaptativos de uso de drogas, nos processos de prisionalização e criminalização dos usuários e no aumento de suas chances de morrerem vítimas de doenças transmissíveis, como a Covid-19.

A Oficina de RD seguiu ocorrendo uma vez por semana e o encontro foi planejado a partir de temáticas geradoras para facilitar os encontros. Foram abordados temas como raça, racismo, experiência de rua, vulnerabilidade social, política, acesso à arte, educação e cultura, sexualidade, gênero, uso de substâncias psicoativas e geração de trabalho e renda. Comumente o planejamento era mudado para atender aos emergentes grupais. A metodologia participativa 


\section{Revista \\ Debates Insubmissos}

buscava trazer assuntos de interesse dos participantes, preferencialmente demandados por eles, e elaborar coletivamente os desafios e potencialidades existentes em cada relação.

\section{CONSIDERAÇÕES FINAIS}

Na Passarela da Cidadania os participantes eram, em sua maioria, pessoas em situação de extrema vulnerabilidade social. Os temas dos encontros possuíam relação com as experiências de vida dos participantes e iam desde experiências coletivas, propondo discussões sobre cuidados necessários de prevenção à Covid-19, às experiências individuais, como as relações familiares, de gênero, raça, sexualidade, orientação sexual e uso de álcool e outras drogas. A oficina tornou-se um espaço importante de acolhimento da diversidade de experiências das pessoas que estavam vivendo na Passarela da Cidadania, de não segregação, de questionamento de preconceitos e estigmas, de viabilização de trocas entre pares, de escuta inclusiva, promovendo, desta forma, saúde mental, ao mediar a melhora das condições de vida daquela população, ao considerar os determinantes sociais que estavam afetando direta ou indiretamente os participantes.

As possibilidades de reflexões geradas a partir da experiência da Oficina de Redução de Danos junto a pessoas em vulnerabilidade psicossocial durante uma pandemia têm sido vastas e necessárias. Um dos maiores desafios foi perceber que propor estratégias de prevenção a uma doença específica, de surgimento recente, não fazia sentido para uma boa parte daquela população vulnerável, na justa medida em que suas existências são atravessadas cotidianamente por outros riscos mais frequentes e, muitas vezes, tão graves quanto a ameaça desta doença letal, que os colocam na condição de viver sob o fio da navalha. Como reduzir os danos de uma possível exposição e não ficar retido no modelo preventivo que tem eficácia para a maioria da população, mas ali encontrava, em muitas situações, ouvidos moucos? Por isso mesmo, os encontros nas oficinas partiram do pressuposto de promover saúde considerando outros aspectos da vida humana para além da ausência de doença, promovendo autonomia financeira através de grupos de geração de renda, acesso à educação, moradia, alimentação, lazer e, principalmente, momentos que visavam proporcionar a escuta psicossocial e a liberdade de 


\section{Revista \\ Debates Insubmissos}

expressão das pessoas em situação de rua. Era preciso valorizar a vida, mediar campos de possibilidade de ser, redesenhar sentidos existenciais, para que proteger-se do vírus viesse a fazer sentido e colocar-se como escolha para os vulnerados. Essas ações relacionaram-se, diretamente, com o conceito ampliado de saúde, ao ter como orientação o cuidado em liberdade, a construção de projeto terapêutico com os usuários, a aposta na coletividade e a não individualização de problemas sociais (RAUPP; CONTE, 2020).

Portanto, como afirma Lancetti (2008), a oficina de Redução de Danos apresenta a clínica numa lógica ampliada, enquanto postura ética do bom encontro, lançando-a para fora do setting tradicional, para fora de quatro paredes. Sua potência está no encontro dos saberes, tencionando os sujeitos a se exporem e se tecerem em coletividade e, assim mediados, pelos seus pares, sejam então capazes de produzir novos modos de vida, mesmo em situações de extrema vulnerabilidade social.

Propor estratégias de promoção de saúde num país de tamanho continental e extrema desigualdade social como o Brasil já é por si só um grande desafio. Contudo, trabalhar com promoção de saúde no ano de 2020, diante de uma pandemia global, do desmonte de políticas públicas de saúde e assistência social, do avanço do fascismo, do negacionismo e de uma estranha glorificação da ignorância e da violência, tornou esse intento ainda mais desafiador. Promover saúde, principalmente em tempos de pandemia, tem exigido, ainda mais intensamente, uma articulação intersetorial e interdisciplinar na construção de estratégias coletivas de cuidado e de solidariedade, visando garantir qualidade das estruturas e equipamentos de trabalho, formação continuada das equipes de saúde para lidar com situações de crise e seus efeitos, além do reconhecimento e valorização dos trabalhadores e trabalhadoras pela área da saúde. É preciso entender o desafio que é ser profissional da saúde em meio a uma pandemia global, valorizar a área da saúde, o SUS e seus trabalhadores e lembrar que os aplausos sozinhos não salvam vidas.

Diante dos desafios e potencialidades dos encontros ocorridos nas oficinas de Redução de Danos em 2020, ressalta-se que a prática da promoção de saúde deve estar associada a uma 
ação que coloca em evidência as desigualdades sociais e os DSS para compor suas estratégias, pois sem isso é ineficaz.

\section{REFERÊNCIAS}

ASSOCIAÇÃO BENEFICENTE REDE COM A RUA. Estatuto Social. Florianópolis: Rede Com a Rua/SC. 2020.

BARATA, R. B. Desigualdades Sociais e Saúde. In: CAMPOS, G. W. S. et. al. (org.). Tratado de Saúde Coletiva. Rio de Janeiro: Ed. Fiocruz, 2009. p. 457 - 486.

BERTONI, Neilane; BASTOS, Francisco Inácio. Pesquisa nacional sobre uso de crack: quem são os usuários de crack e/ou similares do Brasil? Quantos são nas capitais brasileiras?. Rio de Janeiro: ICICT/Fiocruz; 2014. Disponível em https://www.arca.fiocruz.br/handle/icict/10019

BRASIL. Casa Civil. Constituição da República Federativa do Brasil de 1988. Brasília, DF: Presidência da República, 1988. Disponível em:

http://www.planalto.gov.br/ccivil_03/constituicao/constituicao.htm. Acesso em: 12 Ago 2021.

BRASIL. Lei $\mathrm{n}^{\circ}$ 8.080, de 19 de setembro de 1990. Dispõe sobre as condições para a promoção, proteção e recuperação da saúde, a organização e o funcionamento dos serviços correspondentes e dá outras providências. Brasília: Ministério da Saúde, 1990. Disponível em: http://www.planalto.gov.br/ccivil_03/leis/18080.htm. Acesso em 30 de maio de 2021.

BRASIL. Ministério da Saúde. Relatório final da VIII Conferência Nacional de Saúde, 1986.

BRASIL. Ministério da Saúde. Política Nacional de Promoção da Saúde (Documento para discussão). Brasília: Ministério da Saúde, 2002, 60 p. Disponível em:

https://bvsms.saude.gov.br/bvs/publicacoes/politica_nac_prom_saude.pdf. Acesso em 20 de maio de 2021.

BRASIL. Ministério da Saúde. A Política do Ministério da Saúde para atenção integral a usuários de álcool e outras drogas. Brasília: Ministério da Saúde, 2003. 60 p. Disponível em http://bvsms.saude.gov.br/bvs/publicacoes/politica_atencao_alcool_drogas.pdf. Acesso em 20 de maio de 2021.

BRASIL. Decreto ${ }^{\circ} 7.053$, de 23 de dezembro de 2009. Institui a Política Nacional para a População em Situação de Rua e seu Comitê Intersetorial de Acompanhamento e Monitoramento, e dá outras providências. Brasília: Presidência da República, 2009. 
Disponível em: http://www.planalto.gov.br/ccivil_03/_ato20072010/2009/decreto/d7053.htm. Acesso em 20 de maio de 2021.

BRASIL. Departamento Penitenciário Nacional. Levantamento Nacional de Informações de Penitenciárias: período de julho a dezembro de 2019. Brasília, SISDEPE, 2020a. Acesso em 31/05/2021. Disponível em: https://www.gov.br/depen/pt-br/sisdepen

BRASIL. Ministério da Mulher, da Família e dos Direitos Humanos. Nota técnica $\mathrm{n}^{\circ}$ 5/2020/CGRIS/DEPEDH/SNPG/MMFDH. Orientações gerais sobre atendimento e acolhimento emergencial à população em situação de rua no contexto da pandemia do Covid-19. Brasília: MMFDH, 2020b. Disponível em: https://www.gov.br/mdh/pt-br/naveguepor-temas/populacao-em-situacao-de-rua/Atendimento_e_Acolhimento_Emergencial.pdf. Acesso em 20 de maio de 2021.

BUENO, S. Fórum Brasileiro de Segurança Pública. Análise da letalidade policial no Brasil. Anuário brasileiro de Segurança Pública 2019. São Paulo: Fórum Brasileiro de Segurança Pública; 2019. p. 61-63. Acesso em: 25 set 2020. Disponível em: https://www.forumseguranca.org.br/wp-content/uploads/2019/10/Anuario-2019FINAL 21.10.19.pdf

CAMPOS, Gastão Wagner de Souza. Tratado de Saúde Coletiva. Rio de Janeiro: Ed. Fiocruz, 2009, 976 p.

CZERESNIA, Dina. O conceito de Saúde e a Diferença entre Prevenção e Promoção. In: Czeresnia D, Freitas CM (org.). Promoção da Saúde: conceitos, reflexões, tendências. Rio de Janeiro: Ed. Fiocruz, 2003. p.39-53. Disponível em: http://www.fo.usp.br/wpcontent/uploads/AOconceito.pdf. Acesso em 28 de agosto de 2020.

DANTAS, E. S. O. Saúde mental dos profissionais de saúde no Brasil no contexto da pandemia por Covid-19. Interface - Comunicação, Saúde, Educação [online]. 2021, v. 25, suppl 1 [Acesso 31 Maio 2021], e200203. Disponível em:

https://doi.org/10.1590/Interface.200203

FERREIRA, G. Arco Íris em disputa: A “parada da diversidade” de Florianópolis: entre políticas, sujeitos e cidadania. Dissertação (mestrado). Curso de Pós-Graduação em Antropologia Social. Universidade Federal de Santa Catarina, Florianópolis, 2012. Disponível em: https://repositorio.ufsc.br/xmlui/handle/123456789/96250?show=full. Acesso em 30 de maio 2021.

FUNCIA, F.R. Subfinanciamento e orçamento federal do SUS: Referências preliminares para a alocação adicional de recursos. Cien Saude Colet [periódico na internet] (2019/Set). [Citado em 08/05/2021]. Disponível em: 
http://www.cienciaesaudecoletiva.com.br/artigos/subfinanciamento-e-orcamento-federal-dosus-referencias-preliminares-para-a-alocacao-adicional-de-recursos/17339?id=17339

GROLLMUS, Nicholas S.; TARRÈS, Joan P. Relatos metodológicos: difractando experiências narrativas de investigación. Fórum Qualitative Social Research, v. 16, n. 2 , mayo 2015. Disponível em:< file:///C:/Users/Particular/Downloads/2207-9561-1PB\%20(1).pdf>. Acesso em: 28 fev. 2021.

INSTITUTO ARCO-ÍRIS, 1997. Estatuto Social. Florianópolis: Instituto Arco-íris/SC. LANCETTI, A. Clínica Peripatética. São Paulo: Hucitec, 2008, 128 p.

MESQUITA, Fábio. Redução de Danos. Boletim do Instituto de Saúde. BIS - IN. 30 anos da Redução de Danos no Brasil. n. 2, v.1., 94-104, 2020. Disponível em: https://periodicos.saude.sp.gov.br/index.php/bis

MINAYO, M. C. S. Violência e saúde. Rio de Janeiro: editora Fiocruz, 2006. Temas em Saúde Collection.132 p. Acesso em 25 set 2020. Disponível em: http://books.scielo.org MOREIRA, Fernanda G. Redução de Danos e Promoção de Saúde. In: I Seminário sobre a Política Nacional de Promoção da Saúde. 2006, Brasília. Anais eletrônicos. Brasília, 2006. p. $140-143$.

NATALINO, Marco. Estimativa da População em Situação de Rua no Brasil (setembro de 2012 a março de 2020). Nota Técnica do IPEA, nº 73. Brasília: Instituto de Pesquisa Econômica Aplicado, 2020, 20 p.

NÓR, S. .; CAVANUS, A. V. .; ARAÚJO DE SOUZA, G. R. F. . O Instituto Arco-íris e uma crítica ao Projeto Urbano em Florianópolis. arq.urb, n. 21, p. 76-88, 1 maio 2018. Disponível em: https://revistaarqurb.com.br/arqurb/article/view/86. Acesso em 12 Ago. 2021.

PETUCO, D. . As Três Ondas da Redução de Danos no Brasil. Boletim do Instituto de Saúde BIS - IN. 30 anos da Redução de Danos no Brasil. n. 2, v.1. (2), 94-104, 2020. Disponível em: https://periodicos.saude.sp.gov.br/index.php/bis

RAUPP, Luciane; CONTE, Marta. Rodas de Redução de Danos “RD: Cadê você”?

Boletim do Instituto de Saúde BIS - IN. 30 anos da Redução de Danos no Brasil. n. 2, v.1. (2), p. 94-104, 2020. Disponível em: https://periodicos.saude.sp.gov.br/index.php/bis RIGONI, Rafaela; BREEKSEMA, Jost; WOODS, Sara. Limites da correria: redução de danos para pessoas que usam estimulantes; prefácio à tradução inglesa José Arturo Costa Escobar; prefácio da edição inglesa Daniel Brombacher; tradução Bernardo Lisboa Carvalho e José Arturo Escobar. Recife: Escola Livre de Redução de Danos, 2019. 
RIBEIRO, M. M.; BELLINI JÚNIOR, A. C. Conceito de redução de danos em políticas públicas relacionadas a drogas. BIS. Boletim do Instituto de Saúde, v. 21, n. 2, p. 32-39, 1 dez. 2020. https://doi.org/10.52753/bis.2020.v21.34615

SANTOS, Márcia Pereira Alves et al. População negra e Covid-19: reflexões sobre racismo e saúde. Estudos Avançados, n. 34, v. 99, Mai-Ag. 2020. https://doi.org/10.1590/s01034014.2020.3499.014

SCHNEIDER, D. R. et al. Intervenção e Pesquisa em Promoção de Saúde na EJA. Desafios do uso de metodologias emancipatórias. In: COSTA, E. M. (Ed). Bases Conceituais da Saúde [recurso eletrônico]. Ponta Grossa (PR): Atena Editora, 2019, p. 162-179. Disponível em https://www.atenaeditora.com.br/wp-content/uploads/2019/02/e-book-Bases-Conceituaisda-Sa\%C3\%BAde.pdf. Acesso em 15 de maio de 2021.

SCHNEIDER, D. R. Horizonte de racionalidade acerca da dependência de drogas nos serviços de saúde: implicações para o tratamento. Ciência \& Saúde Coletiva, v.15, n.3, p. 687-698, 2010. https://doi.org/10.1590/S1413-81232010000300011

SICARI, A. A.; ZANELLA, A. V. Pessoas em Situação de Rua no Brasil. Psicologia: Ciência e Profissão, v.38, n.4, p. 662-679, Out/Dez. 2018. https://doi.org/10.1590/1982$\underline{3703003292017}$

SÍCOLI, J. L., NASCIMENTO, P. R. Health promotion: concepts, principles and practice. Interface - Comunic, Saúde, Educ., v.7, n.12, p.91-112, 2003. https://doi.org/10.1590/S1414-32832003000100008

TEIXEIRA, C. F. S. et al. A saúde dos profissionais de saúde no enfrentamento da pandemia de Covid-19. Ciência \& Saúde Coletiva [online]. 2020, v. 25, n. 9 [Acessado 31 Maio 2021], pp. 3465-3474. https://doi.org/10.1590/1413-81232020259.19562020.

VARANDA, W.; ADORNO, R.C.F. Descartáveis urbanos: Discutindo a complexidade da população de rua e o desafio para políticas de saúde. Saúde e Sociedade, v.13, n.1, p.56-69, jan-abr 2004. https://doi.org/10.1590/S0104-12902004000100007

XIMENES, Verônica Morais et al. Pobreza multidimensional e seus aspectos subjetivos em contextos rurais e urbanos nordestinos. Estud. psicol. (Natal), v. 21, n. 2, p. 146-156, June 2016. Disponível em https://www.scielo.br/j/epsic/a/L9nhDkCQxgmqkQhJXVFdLvr/?lang=pt\&format=pdf. Acesso em 12 Ago 2021.

WORLD HEALTH ORGANIZATION (WHO). Conferência Internacional sobre Promoção da Saúde. Carta de Ottawa para a Promoção da Saúde. Canadá, 1986. Disponível em: https://bvsms.saude.gov.br/bvs/publicacoes/carta_ottawa.pdf. Acesso em 12 Ago 2021. 
WORLD HEALTH ORGANIZATION (WHO). Conferência Mundial Sobre Determinantes Sociais da Saúde. Diminuindo diferenças: a prática das políticas sobre Determinantes Sociais da Saúde. Brasil, 2011. Disponível em:

https://www.who.int/sdhconference/discussion_paper/Discussion_Paper_PT.pdf. Acesso em 12 Ago 2021.

Submetido: $10 / 06 / 2021$

Aprovado: 13/08/2021 